University of Wollongong

Research Online

Faculty of Law, Humanities and the Arts Papers (Archive)

Faculty of Arts, Social Sciences \& Humanities

$1-1-2016$

The Chinese-Korean co-production pact: collaborative encounters and the accelerating expansion of Chinese cinema

Brian Yecies

University of Wollongong, byecies@uow.edu.au

Follow this and additional works at: https://ro.uow.edu.au/lhapapers

Part of the Arts and Humanities Commons, and the Law Commons

Research Online is the open access institutional repository for the University of Wollongong. For further information contact the UOW Library: research-pubs@uow.edu.au 


\title{
The Chinese-Korean co-production pact: collaborative encounters and the accelerating expansion of Chinese cinema
}

\begin{abstract}
Official film co-production treaties are designed by policymakers to stimulate a range of collaboration and media flows as determinants of country rankings. China, where, technology transfer, and joint funding initiatives in the industry. Since July 2004 , the Chinese government has used this top-down approach to cultural diplomacy as a symbolic tool for advancing Chinese cinema and opening the domestic market to a host of willing international partners. Korean filmmakers in particular have exploited the (often informal) opportunities presented, engaging in vigorous cooperation between film industry firms and practitioners is making significant inroads, is one such case, having fallen outside of the Western-dominated global 'Soft Power 30' index.with Chinese colleagues across all sectors of the production ecosystem. The continuing flow of Chinese-Korean transnational film encounters, underpinned by influential personal networks, resulted in the signing of a formal China-Korea co-production agreement in July 2014. To redress this limited viewpointexamine the efficacy of this policy intervention, this article analyzes a rangethe diversity of film collaborationscollaboration that preceded the 2014 South Korea-China coproductionthis agreement and theirits impact on transnational filmmaking in China. It investigates the strategies used in the remaking of Korean auteur Lee Man Hee's 1966 melodrama Late Autumn (2010), technical innovation in Dexter Digital'sthe VFX-heavy Mr. Go (2013), and the making of Korean megadistributor CJ E\&M's romance drama A Wedding Invitation (2013). These recent examples of transnational co-operation prior) to the signing of this landmark policy instrument illustrate how Korean firms and practitioners are continuing to expand theexpanding the commercial entertainment boundaries of Chinese cinema, and. In so doing, it also reveals how Chinese film companies are enabling the Korean film industry to increasingly internationalize its approach to overseas markets beyond the kind of conspicuous bilateral policy initiatives. This study is intended to add a nuanced layer of complexity to the 'soft power aspirations' of both China and Korea and their links to the film industry in tailored for a globalized cultural economy.
\end{abstract}

\section{Keywords}

korean, production, pact, collaborative, encounters, accelerating, expansion, cinema, chinese, co

\section{Disciplines}

Arts and Humanities | Law

\section{Publication Details}

Yecies, B. "The Chinese-Korean co-production pact: collaborative encounters and the accelerating expansion of Chinese cinema." The International Journal of Cultural Policy 22.5 (2016): 770-786. 


\title{
The Chinese-Korean co-production pact: collaborative encounters and the accelerating expansion of Chinese cinema
}

Brian Yecies*

\begin{abstract}
Faculty of Law, Humanities and the Arts, School of Humanities and Social Inquiry, University of Wollongong, NSW 2522, Australia
\end{abstract}

(Received 4 January 2016; accepted 25 April 2016)

Official film co-production treaties are designed by policymakers to stimulate a range of collaborations, technology transfers, and joint funding initiatives in the industry. Since July 2004, the Chinese government has used this top-down approach to cultural diplomacy as a symbolic tool for advancing Chinese cinema and opening the domestic market to a host of willing international partners. Korean filmmakers in particular have exploited the (often informal) opportunities presented, engaging in vigorous cooperation with Chinese colleagues across all sectors of the production ecosystem. The continuing flow of Chinese-Korean transnational film encounters, underpinned by influential personal networks, resulted in the signing of a formal China-Korea co-production agreement in July 2014. To examine the efficacy of this policy intervention, this article analyzes the diversity of film collaboration that preceded this agreement and its impact on transnational filmmaking in China. It investigates the strategies used in the remaking of Korean auteur Lee Man Hee's 1966 melodrama Late Autumn (2010), technical innovation in the VFX-heavy Mr. Go (2013), and the making of mega-distributor CJ E\&M's romance drama A Wedding Invitation (2013) to illustrate how/Korean firms and practitioners are expanding the commercial entertainment boundaries of Chinese cinema. In so doing, it also reveals how Chinese film companies are enabling the Korean film industry to internationalize its approach to overseas markets beyond the kind of conspicuous policy initiatives tailored for a globalized cultural economy.

Keywords: People's Republic of China; South Korea; film policy; co-production;

\section{Introduction}

Sourcing policy documents and statements published by the People's Republic of China's State Administration of Press, Publication, Radio, Film and Television (hereafter SAPPRFT, formerly known as SARFT - China's media regulator) is relatively easy today. Yet, despite a wealth of such information, there remains a gulf between official policy rhetoric and the radical transformation that the film industry in the People's Republic of China (hereafter China) is experiencing on a weekly basis. This might be considered unsurprising, given the history of the Chinese Communist Party's wider approach to cultural policy, discussed in detail elsewhere (Keane 2010, Zhang 2010, Vlassis 2015, and Meyer-Clement 2015). However,

\footnotetext{
*Email: byecies@uow.edu.au
} 
since the Chinese government's promulgation of The Administration of Sino-Foreign Cooperation in the Production of Films Provisions in 2004, and the extension of the 2003 Closer Economic Partnership Arrangement (CEPA) between China and Hong Kong to the film industry in late 2005, collaboration involving both state-run and commercial filmmakers with ties to international colleagues has made the Chinese film industry increasingly competitive on the global stage. In particular, firms and practitioners working in the Chinese film industry have embraced policy recommendations arising from the Communist Party's plenum of October 2011 aimed at expanding the quantity, quality, and international appeal of the country's media and cultural contents. As a result, Chinese cinema has experienced an exceptional period of expansion largely as a consequence of a series of unprecedented privatization, professionalization, and internationalization processes that are occurring both within and beyond Greater China's borders.

Since the mid-2000s, a host of 'willing collaborators' - national and international investors, firms, and creative practitioners, mainly (but not exclusively) from East Asia - have engaged in various models of collaboration with Chinese companies. But increasingly over the last five years, they have leapfrogged the older practices and policies that marked the state-controlled pre-CEPA era, fundamentally transforming Chinese cinema in dynamic - but uneven - ways. While projectbased, Hollywood-style contracting-out relationships with producers, aimed at competing on price internationally, have long typified the global film trade (Miller et al. 2005, Goldsmith and O'Regan 2005), this approach to filmmaking has entered uncharted waters in China. The nerve center of Chinese cinema is being stimulated in new directions by a number of developments: the rapid expansion of domestic multiplex screens (estimated at 32,000 and rising); the proliferation of online video-on-demand sites (such as Sohu, Youku, Sina, iQiyi, and LeTV) that capture massive audiences with both foreign and domestic films and television shows; and Dalian Wanda Group's acquisition of major exhibition chains in North America (AMC in 2012) and Australasia (Hoyts in mid-2015), as well as its purchase in early 2016 of the production/finance studio Legendary Entertainment (for $\$ 3.5$ billion US in cash) - the biggest Chinese acquisition in Hollywood to date.

In addition, the quantity and diversity of domestic films approved by SAPPRFT continues to proliferate - albeit with due caution. Unprecedented levels of local Chinese product placement are being seen in Hollywood blockbusters such as Iron Man 3 (2013) and Transformers 4 (2014), and top Chinese stars - such as Li Yifeng - are being recruited as 'fan ambassadors' to promote films such as Batman v Superman: Dawn of Justice (2016) alongside product tie-ins with local dairy, household goods and fast-food restaurant brands in China. Once unthinkable, a growing number of new private (including formerly state-owned) practitioners are now operating across all sectors of the industry, and Chinese firms continue to invest in Hollywood companies and vice versa. Even before Dalian Wanda's Legendary Entertainment deal in early 2016, it had already begun co-investing in the US film industry, beginning with the boxing drama Southpaw (2015), starring Jake Gyllenhaal. Despite these developments, private interests by no means dominate China's film scene. The biggest state-owned film studio, the China Film Group Corporation (hereafter CFG), is also a major player in the new commercial entertainment era. Under its current head, La Peikang (former SARFT deputy chairman and head of CFG's China Film Co-Production Company), CFG has invested in the production of Seventh Son (2014), Pixels (2015), Furious 7 (2015, aka Fast and 
Furious 7), and Warcraft (2016). Little wonder that Furious 7 broke all box office records in China when it was released in April 2015, given CFG's dominance in the Chinese market.

Taken in combination, these developments are enabling China to compete on the global stage, albeit in partly inconspicuous ways and with the valuable assistance of one of its most important cultural allies: South Korea (hereafter Korea). The activities analyzed below reveal their mutual interest in expanding the number and quality of film co-productions, and China's desire to engage with a key trading partner well known for its success in developing vibrant and thriving media and cultural industries. Yet, while the rhetoric surrounding Korea's 'soft power success story' and its transnational flows across Asia continue to be debated (for e.g. Chua 2012, Iwabuchi 2013, Keane and Liu 2013, Jin and Yoon 2015), the 'Korean wave' of contemporary popular culture (television dramas, movies, music, fashion, cosmetics, tourism and food, etc.) has achieved a dominant position that many countries envy. ${ }^{1}$ Chinese practitioners, firms and policymakers have increasingly sought

20 to boost the international appeal of Chinese media and cultural contents by integrating lessons learned from foreign competitors and collaborators. As a result of their proven technical capabilities, global experience, availability, affordability and geographical and cultural proximity, Korean film practitioners and companies have provided a wealth of opportunities and resources for their Chinese colleagues - well before the 2014 co-production treaty officially invited them to do so.

With this evolving background in mind, I draw on three brief case studies to reveal how deeply enmeshed Korean and Chinese filmmakers have become throughout the 2010s (and before) in ways that anticipate and underpin the core aspirations of the China-Korea co-production agreement signed in July 2014. First, 30 I investigate the strategies used in the remaking of Korean auteur Lee Man Hee's 1966 melodrama Late Autumn (2010). Second, I analyze the technical innovations employed in Dexter Digital's VFX-heavy Mr. Go (2013), illustrating how Dexter along with other Korean visual effects and digital intermediary firms like Digital Studio 2L, Digital Idea, Macrograph, Moneff - have thrived in the new environ-

35 ment to the extent that they have established ongoing representation in China. Third, and finally, I explore the inconspicuous relationships behind the making of Korean mega-distributor CJ E\&M's romance drama A Wedding Invitation (2013), which systematically reclad an original Korean story in Chinese dress. Through these three case studies, I demonstrate how Korean directors, actors and special

40 effects practitioners are offering their skills to the rapidly expanding Chinese film industry in return for massively increased exposure and investment opportunities. Based on these developments - which have arisen in response to pressures from within a rapidly globalizing industry - this study enquires how the 2014 co-production treaty between China and Korea might build on this established foundation of collaboration and further benefit both film industries in concrete ways.

\section{The forging of Chinese-Korean connections}

Central to the current frenzy of transnational activity in the Chinese film industry are contributions by practitioners from Korea who have made a significant impact on the Asian superpower's film industry ecosystem. For some time now, Chinese 50 firms have been recruiting established Korean directors, of whom Park Yu-hwan, Jo Jin-kyu, Kwak Jae-yong, Hur Jin-ho, Ahn Byeong-ki, and Heo In-moo are the best 
known. The results of these collaborations have included the thriller The Mysterious Family (2016); melodrama Passion Heaven (2016); rom-com Meet Miss Anxiety (2014); romantic dramas A Good Rain Knows (2009) and Dangerous Liaisons (2012) - both with Zonbo Media; Korean horror remake Bunshinsaba (2012, aka Bi Xian) and its 2013 and 2014 sequels; and the romantic comedy The Wedding Bible (yet to be released by Beijing East Light Films in 2016), respectively. Seasoned Korean cinematographer Kim Hyung-gu - of The Host (2006) and Memories of Murder (2003) fame - shot Chen Kaige's Together (2002), while Choi Sangmok was responsible for Ahn's Bunshinsaba 1 and 2. Producer Edward Yi Chi Yun, who developed personal networks in China in the early 1990s while attending the Beijing Film Academy (BFA), has consulted on a number of major films Feng Xiaogang's Assembly (2007) and Aftershock (2010); John Woo's Red Cliff I (2008) and Red Cliff II (2009); Tsui Hark's Flying Swords of Dragon Gate (2011); Hu Guan's The Chef, The Actor, The Scoundrel (2013); Bob Brown and Peng Chang's co-directed Korean-Chinese-US action-thriller Urban Games (2014); and the action-crime-comedy Bad Guys Always Die-(2015), co-produced by leading Chinese and Korean filmmakers Feng Xiaogang and Kang Je-kyu. The personal networks that producer $\mathrm{Yi}$ and his Korean classmates at the BFA cultivated while studying in China, and the contacts they have made since, have paved the way for much of this collaboration.

While the list of Korean actors and actresses appearing in Chinese films over the past two decades is too long to detail here, lesser known collaborations behind the camera include a cohort of Korean post-production practitioners who have made significant inroads in the rapidly expanding Chinese film industry. For example, Seoul-based Digital Idea and Beijing-based Lollol Media both contributed to the visual effects (hereafter VFX) and digital intermediary (aka DI or color grading) work for Tsui Hark's top-performing 3D film Flying Swords of Dragon Gate (2011), as well as the hits CZ12 (directed by Jackie Chan, 2012) and The Chef, The Actor, The Scoundrel. In addition, Korea's CJ Powercast, Next Visual Studio, and Lollol Media (along with Chinese firm Phenom Film) all made major contributions to the VFX and 2D/3D digital intermediary work on director Wuershan's supernatural fantasy-action romance Painted Skin 2: The Resurrection (2012).

One of the biggest box office sensations resulting from Chinese-Korean collaboration is Stephen Chow's fantasy-drama-romance The Mermaid (2016), which as of April 2016 had returned a gross profit of nearly \$526 million US in China alone and a total worldwide gross box office of \$542 million US. For this action-packed VFX-heavy production, Korean company Macrograph (joined by Hong Kong's Different Digital Design and Los Angeles-based Moai Films) completed the spectacular computer-generated imagery (hereafter CGI). Previously, Macrograph - along with Moneff, Locus Corp., and Korean VFX firm Venture 3D - had completed the CGI for the action-packed 3D film Journey to the West: Conquering the Demons (2013), while at least 11 Korean visual and special effects companies, including Macrograph, Dexter Digital, Digital Studio 2L, and Digital Idea, worked on the collaborative hit The Monkey King (2014). In their respective credits, The Mermaid, Journey to the West and The Monkey King boast the longest list of Korean companies and practitioners of any films produced in China, demonstrating the increasing scope of the continuing internationalization of both Chinese and Korean cinema.

In light of this extensive and expanding list of Chinese-Korean film encounters, it came as no surprise when, in July 2014 - the ten-year anniversary of SARFT's 
promulgation of The Administration of Sino-Foreign Cooperation in the Production of Films Provisions - a co-production agreement was signed in Seoul between policymakers from Korea's Ministry of Culture, Sports, and Tourism and China's SAPPRFT. The announcement of the deal followed a high-profile trade summit in Seoul between Korean president Park Geun-hye and Chinese president Xi Jinping. Headlines trumpeting the co-production treaty are difficult to find as the signing was overshadowed by the larger bi-lateral meeting in July 2014 and the subsequent China-South Korea Free Trade Agreement talks held in Beijing in November 2014. Suffice it to say that, at the time, leading film trade publications Variety, The Holly10 wood Reporter, and Screendaily hailed the treaty as a 'landmark agreement'. 2 However, in practice the deal is little more than a thinly-veiled device that would enable Korean films to be classified as 'domestic' in China, thereby circumventing China's protectionist import quotas. ${ }^{3}$ Given that other recent studies of film policy (Parc 2016) and cultural diplomacy (Kang 2015) in Korea have neglected to discuss the 15 implications of the agreement, it seems fitting that the present investigation should attempt to fill the gap.

Like other international policy instruments of its kind that seek to increase training opportunities - as well as to provide location incentives, producer offsets and tax exemptions, and post-production rebates - the 2014 agreement undertakes to 20 stimulate an increasing number of official film collaborations and industry networking initiatives between both nations, and to maximize distribution opportunities for co-produced films in the global market. Under the agreement, a film qualifies as an official co-production after meeting specific requirements from each partner. Official co-productions are considered to be 'domestic' films in both countries, thus 25 enabling them to circumvent existing film quotas that restrict the number of annual screenings of imported, foreign films. On paper, the agreement seeks to promote the development of the Korean and Chinese film industries and to increase the competitiveness of joint productions by facilitating technical cooperation across all sectors of the filmmaking process, including visual and special effects, virtual real-

30 ity, and digital cinema infrastructure.

In reality, however, as Korea already has an established record of technical innovation and a mature film industry ecosystem (see Yecies 2010), the agreement effectively favors Chinese firms in their bid to catch up with international industry standards and adopt the genre-bending story lines for which Korean cinema is so

35 well known. More importantly, as the following discussion illustrates, the collaboration process has already achieved a momentum of its own in the absence of any formal co-production agreement, and it is a moot point whether such agreements will help or hinder the development of two national film industries which already have a successful record of leveraging off each other's particular strengths and defi-

\section{0 ciencies.}

The Korean Film Council (hereafter KOFIC) has been instrumental in creating the atmosphere in which collaborative ventures have flourished. Korean practitioners such as Andy Yoon (CEO, Moonwatcher Films) have been developing personal networks and exploring opportunities for both formal and informal co-productions 45 since 2008 - largely through KOFIC-sponsored events. Yoon is also a KOFIC coproduction mentor (appointed in 2011), leading workshop discussions in annual industry networking events run in Beijing and Seoul. ${ }^{4}$ For practitioners such as Yoon - whose path has crossed the author's several times since 2008 while conducting research in Korea and China - the excitement and hype surrounding the 
treaty have been undercut by the length of time it has taken policymakers to promulgate the formal agreement. Moreover, the content of the agreement appears less significant than the actual efforts and accomplishments of practitioners forging their own collaborative relationships with Chinese partners and making other inroads into the Chinese film industry.

That being said, China's co-production treaties require both domestic and international partners to liaise with SAPPRFT via the China Film Co-production Corporation (hereafter $\mathrm{CFCC}$ ), the chief quasi-government body responsible for the selection and administration of co-produced films. According to most of these agreements, all international (i.e. non-Chinese) partners are required to fund between 20 and $80 \%$ of the total production budget. In Britain's case, representatives from the UK Department for Culture, Media and Sports and/or the CFCC can negotiate wider financial contributions of between 10 and $90 \%$ - to accommodate additional input from a third co-producing partner that may or may not have an existing treaty with China. Regardless of the funding ratios agreed on, producers are encouraged to match creative contributions to their financial commitment.

Unlike similar treaties between China and Australia, Britain, and New Zealand, for instance, the text of the China-Korea agreement is shorter and less detailed than many of its predecessors. It contains 15 articles as well as an explanatory annex that define subjects covered in the agreement, including: general aims and benefits, such as the removal of local market/and import barriers; approval processes; creative contributions from a film's cast and crew; sharing of computer graphics, virtual reality and/or digital cinema skills and technologies; production budgets and in-kind costs; and guidelines for contributions made by (minor) third parties. Whereas China's treaties with Australia and New Zealand contain similar wording, guidelines, and restrictions, its agreement with Korea omits (for example) criteria relating to the composition of soundtrack music, creating opportunities to include a wider than normal/range of international musicians in a given production.

From the Chinese perspective, co-productions are subject to a lengthy threestage approval and completion process, involving extensive paperwork, online submissions, and other administrative processes. (SAPPRFT now requires project coordinators to submit all documentation for each stage of a given production simultaneously via its E-Government Network website (http://dy.chinasarft.gov.cn/) and also to CFCC - in hard copy.) First, co-producers must receive project and script approval (a 'Film Project Establishment Notice' and 'Chinese-Foreign Film Co-production Permit'), which grants them provisional compliance and authorization to shoot the film. Second, they must obtain government consent for the 'Official Shooting Plan', which enumerates the specific production details, such as shooting locations, logistics, and a full list of the cast and crew (including their personal details and filmographies). Third and finally, producers must seek final approval (a 'Film Review Decision' and 'Film Public Screening Permit') from SAPPRFT as well as written approval from KOFIC. Additional administrative and approval processes - prior to SAPPRFT/CFCC approval - are required at the provincial or municipal level depending on where the Chinese partner is based. Given this extraordinarily complicated process, it is not surprising that so few producers on both sides have pursued this formal avenue for collaboration.

Although the China-Korea treaty (available at: www.koreanfilm.or.kr/jsp/coPro duction/treaties.jsp; and www.chinahollywood.org/china-co-production-treaties) sets out its aims succinctly, the annex to the agreement provides concrete details about 
the application process which are missing from similar treaties, which tend to focus on the mutual benefits to be gained from increasing awareness of each other's film industry and respective cultures. However, like most film policy instruments, the real importance of the agreement lies in the additional momentum it gives to the shifting of film collaborations away from the 'offshoring' or 'runaway productions' of the past, to the internationalization that is now an established component of Anglophone film production. In doing so, it also shifts the industry away from a limited output of state-sponsored propaganda films toward the status of an economic commodity augmented by knowledge and technology transfers, as well as the creative ideas and professional practices contributed by a host of willing collaborators from Korea.

15 Despite the best-laid plans of bureaucrats and operatives in both countries, this continuing shift of money, talent and technological know-how is by no means an automatic and orderly process. However, after discussing the implications of the agreement with many Korean and Chinese film industry representatives during multiple visits to China and Korea, the author believes that the two countries are on

20 the cusp of something that differs radically from the experience of other national cinemas and some of the particular cultural diversity and theoretical framework settings that have received considerable attention in the past (see, for example, Moran 1996 and Jäckel 2000). More specifically, as the present article demonstrates, the China-Korea connection remains more robust and enmeshed than China's links 25 with any of the other countries with which it has a co-production treaty; in late 2015 these included: Australia (2007), Belgium (2012), Britain (2014), Canada (1987), France (2010), India (2014), Italy (2004), South Korea (2014), Malta (2015), Netherlands (2015), New Zealand (2010), Singapore (2010), and Spain (2014). Official co-production (as well as unofficial collaborative) films resulting

30 from these other agreements are few and far between. At the same time, and despite the doomsaying common in the Chinese press and echoed in a recent China Daily headline, 'It's Hollywood, silly!'5 - a reminder of how Hollywood blockbusters have historically dominated the global box office - the 2014 treaty has circumvented, or even partly assisted in the transformation of pre-existing tensions

35 between state ideology and official film policy, on the one hand, and a new era of commercialism in China.

To enable us to look forward and to begin imagining the types of new films and other forms of collaboration that the 2014 Korea-China co-production agreement will encourage, it may be useful to look back at some of the key films that 40 form the background to this new policy instrument. Among an increasing number of bilateral film encounters, three films stand out for the lessons that they offer: Late Autumn (2010), Mr. Go (2013), and Wedding Invitation (2013). Drawing them into the larger discussion offers an opportunity to underscore some of the tensions and contradictions inherent in cultural policy change.

\section{On the road again}

Late Autumn is a Korea-US-Hong Kong co-production remake of Korean director Lee Man-hee's legendary 1966 arthouse melodrama of the same title. This road drama explores the relationship between a man on the run and a female prisoner on a three-day prison furlough. Predating the 2014 agreement by four years, it is a key co-production that attempted to appeal simultaneously to audiences in Korea, Hong 
Kong, and China. The film was directed and written by Kim Tae-yong of Korean horror-drama Memento Mori (1999) fame, and produced by seasoned Korean producer Lee Joo-ick, whose company, Boram Entertainment, is at the forefront of Korea's international co-production scene. Late Autumn was co-produced by Hong Kong heavyweights Shi Nansun (former wife of action director Tsui Hark), and Pang Ho-cheung, along with prominent Korean music director and investor Cho Sung Woo. The project built on existing relationships that Lee had established with Chinese partners in his earlier international co-productions, such as Hark's Seven Swords (2005), and Chi Leung 'Jacob' Cheung's Battle of the Warriors (2006), and was given additional international heft by his casting of leading Chinese actress Tang Wei and Korean television heart-throb Hyun Bin. An acknowledged heavyweight, Late Autumn added substance to bilateral talks about an official co-production agreement when the issue first emerged in August 2011. 6

While Korean filmmakers are well known for their experimentation with genre, Late Autumn returns to classic genre conventions, focusing on a simple story line featuring an international cast in a story set against the idiosyncratic backdrop of Seattle, USA. Although one critic panned the film's 'clumsy ambition to "internationalise" South Korean cinema', 7 Late Autumn's relative commercial success outside of Korea points to the domestic industry's growing expansion in the Chinese market, not only giving policymakers a lead in shaping the 2014 co-production agreement, but also offering encouragement to a string of Chinese road films that have been shot on locations outside of China and have also benefitted from the incentives and rebates offered there.

The film follows three days in the life of a Chinese woman, Anna (played by Tang Wei, who gained notoriety for her controversial role in Ang Lee's erotic spythriller Lust, Caution (2007)), who is serving a prison term in California for murdering her husband. During a weekend furlough to attend her mother's funeral in Seattle, she meets a young Korean gigolo, Hoon (played by Hyun), who is eluding the enraged husband of a wealthy Korean client. While it failed at the Korean box office, Late Autumn became the highest grossing Korean film released on the Chinese film market, creating a box office record of over $\$ 9.5$ million US (60 million RMB) in takings over a two-week period in March 2012. ${ }^{8}$ This box office performance, which brought in almost double its production budget, sent a strong message to domestic and international players eyeing the Chinese market: make your productions low-budget and set them on the road, where incentives and crews on location can assist with the production. ${ }^{9}$

The film cuts between Anna and Hoon ensconced in their separate worlds during their stay in Seattle. They soon reunite and explore some of Seattle's landmarks, including the farmers market and Lake Union waterfront, at which time Anna reveals her life story to Hoon in Chinese. He responds with the occasional 'hao' (good) and 'huai' (bad) - the only Chinese words he knows. The pair makes a pact to meet at a particular highway rest stop after Anna is released from prison. However, Hoon fails to appear on the appointed day.

Was the making of Late Autumn the result of 'clumsy ambition' or a calculated strategy for survival in a highly competitive industry? Time will tell. However, as a Korean melodrama-cum-road movie made in the US by local and Hong Kong crews - an arrangement which enabled it to be released in China as a SARFT-approved 'local' film - Late Autumn replaced the 'national' content characteristic of domestic Korean productions with a strong infusion of 'transnational' elements 
extending to actors, locations, and dialog. More critical than this transnational mix, however, was the production strategy that other Chinese filmmakers have quickly learned from and incorporated into subsequent road pictures, including Lost in Thailand (2012, shot in Chiang Mai), Up in the Wind (2013, filmed in Nepal), Old Boys: The Way of the Dragon (2014, filmed in New York), and especially Finding Mr. Right (2013, shot in Vancouver, but set in Seattle and also starring Tang Wei, who married Kim Tae-yong, the Korean director of Late Autumn). Each of these transnational initiatives was eligible for policy-based local tax incentives, shooting rebates, and advance onsite assistance that served as additional lures to the locations chosen.

\section{Size does matter}

The sports-fantasy drama Mr. Go (2013) is Korea's first feature film wholly shot in $3 \mathrm{D}$, and the first commercial $3 \mathrm{D}$ film jointly produced by Korea and China - and one of the first such projects to employ a $3 \mathrm{D}$ producer to liaise between crewmembers and camera teams throughout all stages of the workflow process. Inspired by

20 Korean cartoonist Heo Young-man's comic book The Seventh Team (1984), Mr. Go anthropomorphizes the life of an aging circus gorilla named Ling-ling (aka Mr. Go) who has learned Chinese as well as how to play baseball from Wei-wei, a young female ringmaster (played by Josie Xu, known for her roles in other films featuring generous use of VFX: CJ7 (2008), Future X-Cops (2010), and Starry Starry Night

25 (2011)). Released simultaneously in both countries only one month after the signing of a co-production MOU in June 2013, the project played a noteworthy role in advancing relations between the Chinese and Korean industries. All eyes were on this VFX-laden blockbuster, which - although the filmmakers may not have realized it at the time - established the critical early groundwork for the Korea-China co-production treaty following the start of talks in August 2011.

In the story Wei-wei inherits the circus after her grandfather dies in the real-life Sichuan earthquake that occurred in May 2008. To evade her grandfather's gambling debts (accumulated by betting on Korean baseball games), Wei-wei relocates the circus troupe to the Yanbian Korean Autonomous Prefecture, an area inhabited

35 by ethnic Koreans. One day, a cunning recruiter appears, and lures Wei-wei and Ling-ling to Seoul to play for the real-life Doosan Bears baseball team. The film focuses on the culture shock experienced by Ling-ling and the Korean Baseball League following his introduction to the game. Eventually, Wei-wei's younger and more aggressive circus gorilla, Letting (aka 'thunder'), appears as a contender in 40 the same league - brought to Korea by a Chinese gangster determined to collect Wei-wei's Chinese debts. Letting's arrival threatens Mr. Go and his team's winning streak, resulting in a final showdown. Yet, Ling-ling prevails and helps the Doosan Bears win the championship. In the end, the debt collector is deported back to China for laundering money, and the conniving recruiter is jailed but then released 45 on good behavior. Letting is sent to the Seoul Zoo, and finally Wei-wei and Lingling return to Yanbian to live happily ever after.

Although it failed to exceed box office and audience expectations in both Korea and China, the story behind $M r$. Go's production and the company behind it - Dexter Studios - are key elements in this evolving policy tale of two filmmaking nations. Mr. Go was directed by Kim Yong-hwa, who had debuted a decade earlier with the comedy Oh Brothers (2003) before cementing his reputation with the 
romantic comedy 200 Pounds Beauty (2006) and the sports-drama Take Off (2009) - both box office hits made with digital special effects created by Korea's Eon Digital Film. Mr. Go, for which Kim was also the screenwriter, film editor, and executive producer, is Kim's fourth and most ambitious film to date. It was for this project, involving a giant gorilla created with 3D and advanced VFX, that Kim established his own company, Dexter Digital (under Dexter Studios, established in 2007), in 2010 with consulting assistance from Kim Tae-yong, a senior CGI specialist and animation software developer (2003-2010) for the US VFX firm Rhythm and Hues Studios - best known for its cutting-edge work on Ang Lee's 2012 Oscar-winning Life of $P i{ }^{10}$ Like Eon, Kim aimed to model Dexter on New Zealand's venerable Weta Workshop and its digital VFX firm, Weta Digital, seeking to attract international directors and their effects-heavy blockbusters. ${ }^{11}$

For both gorillas, Kim sought to create realistic creatures with the type of complex fur that looks natural to the human eye - developed with a CGI software tool similar to that used to animate Sulley's turquoise fur in Pixar's Monsters, Inc. (2001), as well as drawing on the hair simulator that Kim Tae-yong developed at Rhythm and Hues for Garfield (2004), Ring 2 (2004), and The Chronicles of Narnia (2005). ${ }^{12}$ After approving the prototypes, which Kim developed over 18 months with around \$1.4 million US raised from Korean government and private investors, Showbox - one of Korea's 'big four' vertically integrated film investment, production and distribution companies - joined the project and gave $M r$. Go the green light for full-scale production. In total, the film spent three-and-a-half years in production and cost an estimated \$25 million US to make (about one-fifth of Life of $P i$ 's total budget) - around half of which was utilized for the research and development of VFX hardware and software through Dexter Digital.

Kim's personal networks in Korea and China (aided primarily by producer Yi Chi Yun), enabled him to involve other key players in the Chinese film industry such as director Feng Xiaogang and Huayi Brothers, one of China's largest private entertainment companies, which became a major investor in $M r$. Go. Huayi Brothers were interested in working with Kim following the relative success of his 200 Pounds Beauty at the Chinese box office (generating 2 million Yuan, a healthy sum at the time). They shared Dexter and Showbox's vision for pooling financial and technical expertise and transforming the $M r$. Go project into a successful KoreaChina blockbuster co-production. Huayi Brothers eventually invested around \$5 million US, significantly increasing the likelihood that $M r$. Go would receive SAPPRFT censorship approval, as well as a subsequent wide release in China. ${ }^{13}$ Other crucial financial support was gained from KOFIC's International Co-production Incentive and P\&A feature film and animation dubbing schemes, as well as KOCCA's Culture Technology (CT) Research \& Development Program. By drawing on this tangible pool of support offered to filmmakers by the Korean government, Kim was able to build his company into a cutting-edge Asian and digital VFX post-production firm in the mold of Peter Jackson's Weta Workshop.

Although completed Korea-China collaborations such as Mr. Go may not have been celebrated - or even explicitly acknowledged - during the signing of the 2014 bilateral co-production agreement, the film is nevertheless significant because the project brought the two industries into a more intimate relationship than many insiders could have imagined at the time. That connection was further strengthened when real estate giant and (now) international multiplex cinema chain Wanda Media purchased a $\$ 10$ million US stake (13.3\%) in Dexter Digital in April 
2015. ${ }^{14}$ To further leverage Dexter's offerings in China, Legend Capital - the chief shareholder of Lenovo computers, and a substantial Chinese venture capital firm in its own right - also invested $\$ 10$ million US (13.3\%) in Dexter Studios in July 2015. ${ }^{15}$ And, given Late Autumn's success in China, and Lee Joo-ick's international experience, it is unsurprising that Lee is now a major producer with Dexter China, Dexter Studio's China outpost.

As a result of this cultural policy-driven venture, Showbox and Huayi Brothers are currently planning a slate of co-productions - the result of their own inter-company film cooperation agreement signed in early 2015 - which will continue to

10 transform the ever-expanding commercial face of Chinese cinema. Dexter's experienced 3D and post-production staff will no doubt play a key role in the pre-visualization and early camera-planning stages of these films, as they did for previous large-scale films produced by Huayi Brothers such as Journey to the West and The Taking of Tiger Mountain.

\section{Remade in China}

Finally, key actors such as CJ E\&M - the leading member of the 'big four' vertically integrated corporate players in the Korean film industry (along with Showbox, Lotte Cinema, and N.E.W.) - have been contributing to the bilateral relationship through films such as $A$ Wedding Invitation (2013). This romantic melodrama piv-

20 ots around high-school sweethearts who break up to pursue their dream careers. Before saying goodbye, the couple decides to reunite five years later - that is, if they are still unattached. Upon the proposed reunion date, Qiaoqiao (played by Bai Baihe) has achieved fame as a designer in Shanghai, while Li Xing (played by Eddie Peng) has realized his dream of becoming a famous chef in Beijing. In a 25 twist, Li Xing reveals his commitment of marrying another woman, giving Qiaoqiao two weeks to change his mind. After Qiaoqiao succeeds in her quest, the career-oriented couple make a new pact to marry each other in another five years if both are still unwed. When that time comes, however, a further obstacle arises and the drama continues.

30 CJ E\&M managed this project in conjunction with Chinese companies CFG and C2M, employing a more hands-on approach than they had used for their first co-production with China, Sophie's Revenge in 2009 (which earned approximately $\$ 15$ million US - double its production budget - in China). ${ }^{16} \mathrm{~A}$ Wedding Invitation was directed by established Korean director Oh Gi-hwan and, although it employed 35 an all-Chinese cast, the core creative and production staff - including the director, cinematographer, editor, and production designer - were almost all Korean. Loosely based on Oh's 2001 hit The Last Present, the screenplay for A Wedding Invitation was rewritten and thus localized to fit a contemporary Chinese context. And this time, it worked. Although the film underperformed in Korea, the box office takings 40 in China more than compensated for it, garnering \$31 million US in April 2013 and making it the highest grossing Korea-China co-production at the time. ${ }^{17}$ As a result of its success in the Chinese market, and given that it was released prior to the signing of the official 2014 agreement, A Wedding Invitation (2013) has become a model for other filmmakers to emulate - with or without assistance from their 45 governments.

Beyond the guidelines offered by any policy agreement, the development and production strategies adopted by CJ E\&M since 2009 have minimized the 
cross-cultural, communication, and practical clashes that occur when mixing crews of different nationalities and making films for simultaneous appeal to audiences in multiple countries. Although most practitioners who had creative input into $\mathrm{AWed}$ ding Invitation in the planning stages were Korean, the scriptwriter and leading actors were all ethnic Chinese, including Taiwanese-Canadian actor Eddie Peng and Chinese actress Bai Baihe. During the pre-planning stages, CJ E\&M content developers conducted detailed research on Chinese audiences to learn more about their tastes in films - an everyday practice in Hollywood, but a relatively new marketing strategy for the Chinese film industry.

The joint project provided CJ E\&M with an opportunity to localize a universal story - never an easy task. As those familiar with $M r$. Go (and Chinese culture) will know, its baseball-centric theme underwhelmed Chinese audiences simply because baseball is not a popular sport in China. As a result of its marketing efforts, A Wedding Invitation has secured a reputation as one of the first KoreaChina co-productions to customize a story that appeals specifically to Chinese audiences and the sentiments that underpin their culture - data researched at a granular level (Ma 2013). This collaborative film encounter not only struck a chord with Chinese audiences (evidenced by its box office performance), but its production approach pushed the bilateral relationship beyond the conventional strategy of importing stars and/or locations as 'exotic' accessories into an otherwise wholly domestic film. In these ways, $A$ Wedding Invitation has done more for the future of co-productions than any single film policy or incentive could ever achieve.

Two years on, the production context of $A$ Wedding Invitation still offers an ideal model for Korean-Chinese co-productions. The producer's brief is a simple one: find a good story (one that has already proven itself with Korean audiences), and then revise it with assistance from a Chinese screenwriter who understands Chinese culture and society. Remove all specifically Korean content from the original film, and then employ experienced filmmakers (who may or may not be Korean nationals) to make the film for a Chinese audience. This formula has become the key to success for Korean filmmakers wanting to break into the China market, as well as for Chinese filmmakers and firms aiming to leverage the creativity and technical knowhow for which Korean cinema - in the post-censorship (i.e. post1996) era - is highly regarded around the world.

This tried-and-true approach to co-productions has continued throughout 2014 and 2016, and embraces remakes of older romances and rom-coms as well as new releases, including Dancing Princess (2005), Cyrano Agency (2010), Architecture 101 (2012), Marriage Blue (2013), and Miss Granny (2014), which have all proved especially popular with Chinese audiences. When 20 Once Again (2015), a localized version of Miss Granny co-produced by CJ E\&M and Beijing Century Media, was released in China in early 2015, it generated \$59 million US, making it the highest-earning Korea-China co-production to date and placing it firmly among China's top ten (at number 9) highest grossing romantic comedies ever. ${ }^{18}$ The original story's concern with family relationships, romantic love and nostalgia for lost youth, and the basic plot dealing with a woman in her 70s who is magically transformed into a 20 -year-old girl, were all retained, but the original script was modified to suit the socio-cultural tastes of Chinese audiences. In a canny move, the filmmakers cast Lu Han - a former member of the immensely popular pan-Asian boy band EXO - as a rock musician, putting 20 Once Again on the radar of the huge numbers of EXO and other K-pop fans in China. This comic fantasy family 
drama was directed by Leste Chen, one of the hottest young Taiwanese directors in China - already well known for directing the mystery-thriller The Great Hypnotist (2014) - thus increasing the film's potential appeal at home and abroad.

\section{Conclusion: whither film policy?}

The Korea-China film collaborations discussed in this article have unfolded on multiple levels, bringing together creative talent involving producers, directors, and actors as well as action, visual effects, and post-production specialists and cinematographers on an unprecedented scale. These bilateral film encounters have

10 occurred largely without any intervention or guidance from official co-production policy agreements and, as a result, have fallen outside of the aims and objectives of a formal policy instrument. The 2014 co-production treaty has thus been established over the top of this critical foundation formed by a wealth of previous filmmaking activity. As this study has shown, the long-term success of any film policy 15 instrument requires far more than words on paper - challenging cultural policy scholars and critics to situate the case studies presented here within existing theoretical frameworks.

The opportunities for Korean film practitioners to work on the long list of Chinese films discussed here and elsewhere (see Yecies and Shim 2016) have grown

20 from tiny seedlings - the contacts and friendships that a handful of aspiring Korean filmmakers made while studying at the Beijing Film Academy during the early-tomid-1990s. The professional inroads made by these now major players have enabled themselves and others throughout the Korean film industry to become some of the most active practitioners and companies in China today. In this way, Chinese

25 cinema is continuing to expand, leveraging off talent and expertise from some of its Asian neighbors without relying solely on bureaucratic policy agreements to facilitate the acquisition of privileged insights into a partnering country's market and the sharing of advanced creative ideas and technical expertise. In the case of Korea and China, these things have long been happening on their own.

30 Nearly all of the pre-2014 films discussed above have involved informal or unofficial agreements and collaborative initiatives rather than a predetermined set of government regulations. The filmmakers have 'made do' by forging company-tocompany deals via informal personal networks, allowing the parties involved to benefit from their existing access to different types of market channels. In following 35 this path, these and other bilateral film projects have created stronger bonds between the two industries, particularly with respect to resisting the US dominance of the film and cultural industries while also fostering dialogue, promoting networking opportunities, and informing future policy development in the Asian region.

While, on paper, the Korea-China agreement promises to provide deep and privileged access to their respective markets, in reality, the hard work has only just begun. As we have seen, the quest for the consummate project and the advanced communication and technical skills required to complete it is driving corporate investors to showcase elements of local cultural identity from within China's creative industries. Nevertheless, the official 2014 agreement may not be as much of a 45 'landmark' as trade articles suggest - nor its goals of improving economic and cultural relations between the two nations, and potentially increasing awareness of each other's film industry and respective cultures. The China-South Korea FTA is likely to prove far more pertinent to this end. Thus, the most effective method of 
developing a collaborative film project still seems to be the exploitation of personal networks.

In today's China, the economic benefits of engaging in co-productions seem more crucial than pursuing a collaborative cultural experience - not because of the opportunity to compound funding sources promised by co-production policies, but rather to enable Chinese producers and large firms to make bigger and more technically savvy feature films that transcend the types of production made under the aegis of the state-controlled industry prior to CEPA. Moreover, the 'national' status achieved by a formal international co-production is the most desirable outcome, as it provides unprecedented access to domestic markets and overseas audiences that might otherwise be restricted by local censorship and import regulations. On top of this, genre choices are changing and expanding in China - thanks in part to the technical expertise and creative nous of the Korean firms and practitioners that have been working in China and/or with Chinese partners during the past decade. In these ways, Chinese films are beginning to show an increasing ability to compete with better-funded US productions and also the novel genres for which Korean cinema is known. At the same time, Chinese companies are benefitting progressively from their investments in the US and Korean markets.

This being said, there are still obstacles to overcome. For some producers and filmmakers who are used to working solely with their own nationals, international co-production agreements are impractical for a variety of reasons: they are too complex; they threaten other incentives available in a partnering country; producers have difficulties negotiating the divergent requirements of two or more partnering governments; crews from different cultures and language backgrounds are usually challenging to manage; and negotiating complex legal agreements increases overall costs. Nevertheless, despite these challenges, the geographic and cultural proximity of China and Korea and their minor time zone difference encourage working together. More importantly, catering to only one nation's audience at a time - as in the case of $A$ Wedding Invitation discussed above - increases the all-important local identity factor without alienating international audiences and sacrificing costs.

Now that the bilateral agreement has been signed, the co-production treaty is expected to provide new opportunities for a large tranche of both industries - for all of the abovementioned reasons. Nevertheless, many of the industry players from both countries that I've talked with over the last 36 months actually see the 2013 MOU and 2014 agreement as a hindrance to bilateral development and collegiality - precisely because of the bureaucratic threats that formal policy implementation pose. In addition, the economic benefits of pooled resources and reduced costs estimated to be a fraction of producing films in the US - can quickly evaporate because of divergences between local and foreign production methods. On the ground and in their own way, Chinese filmmakers are a talented and experienced bunch. However, production crews on both sides of this agreement still have a lot to learn about each other's local customs and traditional operating methods. In other words, appropriate expectations and reasonable targets, achievable through industry experience and personal networks, are needed for international collaborations to succeed - especially given the Chinese and Korean governments' divergent approaches to censorship and media regulation more generally.

Nevertheless, for the remainder of the 2010s, the situation looks like a win-win scenario for both countries. Korean practitioners have contributed to the expansion of Chinese cinema in terms of the refinement of genres, themes and story lines, as 
well as technical skills, and Chinese film companies have enabled Korean cinema to increasingly internationalize its approach to overseas markets. In other words, Chinese cinema is well on the way to fully embracing a new chapter of transnational cinema in both the economic and cultural sense. In these ways, both Korean and Chinese national cinemas are undergoing a major makeover as Chinese filmmakers and firms leverage the innovative esthetic qualities and export-oriented expertise for which Korean cinema has become celebrated around the globe since the censorship of domestic films was ended in 1996. In this new cultural and commercial arena, Korea's global experience and success with its own brand of style and technical prowess has been instrumental in developing its collaborative relationship with China.

\section{Acknowledgements}

15 The author thanks Michael Keane, Terry Flew, Aegyung Shim, Nobuko Kawashima and the anonymous referees for their valuable suggestions on earlier drafts of this paper, as well as Miao Xiaotian (President, CFCC), Susan Xu (Vice President, CFCC), Andy Yoon (President, Moonwatcher), Kevin Chang (Chairman, Association of Film Commissioners International-AFCI), Korean producer Edward Yi Chi Yun, and Chuck Chae and Peter Ahn, senior technicians from Dexter Digital, for sharing their valuable insights on this evolving subject.

\section{Funding}

This work was supported by the Australian Research Council [grant number DP140101643].

\section{Disclosure statement}

AQ225 No potential conflict of interest was reported by the author.

\section{Notes}

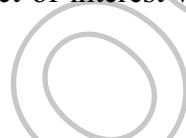

1. Insightful studies of the Korean wave (aka Hallyu) include Chua and Iwabuchi 2008, and Kim 2013.

2. See: China and South Korea Sign Co-Production and Import Deal Patrick Frater; and Clifford Coonan, South Korea, China Sign Landmark Co-Production Pact (3 July 2014); and Noh, J. 2014. Screen daily (4 July 2014). Korea, China sign co-pro agreement. Available from: http://www.screendaily.com/news/korea-china-sign-co-pro-agree ment/5073840.article.

3. In 2016, China's quota of foreign films includes 34 revenue-sharing films per year, while Korea's screen quota regime requires all cinemas to show domestic films for a minimum of 73 days per annum.

4. At the time of writing, Moonwatcher is co-producing Legend Heroes, an animated children's TV series, and Fly, Superboard, a feature animation for theatrical release - both of which combine CGI technology and expertise from Korea and investment from China Film Group.

5. Fan, Xu. 'It's Hollywood, silly!' China daily (9 July 2015). Available from: http://usa. chinadaily.com.cn/epaper/2015-07/09/content_21230399.htm.

6. Noh, J. 2013. 'South Korea and China sign tentative co-production pact', Screen daily, 18 June, http://www.screendaily.com/news/south-korea-china-sign-tentative-co-pro-pact/ 5057476.article [Accessed 2 July 2015].

7. Elley, Derek. 'Late Autumn' Film Business Asia (21 October 2010). Available from: www.filmbiz.asia/reviews/late-autumn [Accessed 3 February 2014].

8. Hwang, Hei-rim. 'Late autumn becomes the all-time highest grossing Korean film in China.' Korean cinema today (13 April 2012), Available from: http://koreanfilm.or.kr/ 
webzine/sub/news.jsp?mode=A_VIEW\&wbSeq=106\#sthash.jd8Q5pw2.dpuf [Accessed 6 April 2015].

9. While shooting in Seattle with local crews and equipment hire, Late Autumn's producers qualified for a 30\% tax rebate through the Washington Motion Picture Production Incentive Program. Available from: http://washingtonfilmworks.org/funding/productionincentive-program.

10. Not to be confused with the Korean film director of Late Autumn, Kim Tae-yong, who is married to Tang Wei.

11. See KIM Su-yeon. 'Visual Effect Creators/Dreaming of Another WETA/EON DIGITAL FILM.' 1 November 2009. Available from: http://koreanfilm.or.kr/jsp/news/re ports.jsp?blbdComCd $=601008 \&$ seq $=127 \&$ mode $=$ VIEW .

12. See Kim Tae-yong's home page. Available from: https://sites.google.com/site/taey ongkimshomepage/ [Accessed 14 May 2015]. Drawing on technical input from Kim Tae-yong, Dexter has also developed a water software tool that was utilized in the VFX for Chinese blockbusters The Taking of Tiger Mountain (2014) and Monkey King (2014).

13. Ma, Kevin. 7 October 2013. 'Korean cinema, Chinese characteristics.' Film Business Asia, Available from: http://www.filmbiz.asia/news/korean-cinema-chinese-characteris tics [Accessed 22 July 2014].

14. See Kil, Sonia. 3 April 2015. 'China's Wanda Takes $\$ 10$ Million Stake in Korean VFXHouse Dexter.' Available from: http://variety.com/2015/biz/asia/chinas-wandatakes-10-million-stake-in-korean-vfx-house-dexter-1201465914/ [Accessed 23 July 2015].

15. Frater, Patrick. 'China's Legend Capital Invests in Korean VFX Firm Dexter Studios' Variety 21 July 2015. Available from: http://variety.com/2015/biz/asia/legend-capital-in vests-in-dexter-studios-vfx-1201544591/.

16. Sophie's Revenge, CJ E\&M's first co-production after establishing a Beijing office in 2009, involved actor So Ji-seop and several Korean crewmembers: colorists Lee Yonggi and Ethan Park (from HFR), and sound engineer Kim Seok-won (from Bluecap Soundworks). Although it was a box office success in China, some Korean critics panned the film for aping the conventions of Korean romantic dramas. See Lee, Hyowon. 'Sophie's Revenge' Satisfies to a Point.' The Korea times (20 August 2009). Available from: http://www.Koreatimes.co.kr/www/news/art/2009/08/135 50426.html [Accessed 2 March 2015].

17. Bingbin, Han. 'A Touch of Seoul in Chinese Films.' China daily USA (11 December 2014). Available from: http://usa.chinadaily.com.cn/epaper/2014-12/11/con tent_19066937.htm [Accessed on 11 February 2015].

18. Hendriks, Priscilla. “"20, Once Again!” Tops Charts.' On Screen Asia (11 February 2015). Available from: http://www.onscreenasia.com/article/20-once-again-tops-charts/ 16657 [Accessed 6 March 2015].

\section{References}

Yecies, Brian and Shim, Aegyung, 2016. The changing face of Korean cinema, 1960-2015. New York: Routledge.

Chua, B.H., 2012. Structure, audience and soft power in East Asian popular culture. Hong Kong: Hong Kong University Press.

Chua, B.H. and Iwabuchi, K., eds., 2008. East Asian pop culture: analysing the Korean wave. Hong Kong: Hong Kong University Press.

Goldsmith, B. and O'Regan, T., 2005. The film studio: film production in the global economy. Lanham, MD: Rowman and Littlefield.

Iwabuchi, Koichi, 2013. Against banal inter-nationalism. Asian journal of social science, 41 (5), 437-452.

Jäckel, Anne, 2000. Film policy and cooperation between east and west: the case of France and Romania in the nineties. International journal of cultural policy, 7 (1), 131-150.

Jin, Dal Yong and Yoon Kyong, (2015, Online First 2014). The social mediascape of transnational Korean pop culture: Hallyu 2.0 as spreadable media practice. New media and society. 
Kang, Hyungseok, 2015. Contemporary cultural diplomacy in South Korea: explicit and implicit approaches. International journal of cultural policy, 21 (4), 433-447. doi:10.1080/10286632.2015.1042473.

Keane, M., 2010. Re-imagining China's future: soft power, cultural presence and the East Asian media market. In: D. Black, S. Epstein, and A. Tokita, eds. Complicated currents: media production, the Korean wave, and soft power in East Asia, Monash University EPress.

Keane, Michael A. and Lui, Bonnie Rui, 2013. China's new creative strategy: the utilization of cultural soft power and new markets. In: Anthony Y.H. Fung, ed Asian popular culture: the global (dis)continuity. London: Routledge, 233-249.

Kil, S., 2015. China's Huayi inks co-production pact with Korea's showbox. Variety, 26 March, Available from: http://variety.com/2015/film/news/chinas-huayi-inks-co-produc tion-pact-with-koreas-showbox-1201460643/ [Accessed 2 July 2015].

AQ6

Kim, Youna, ed., 2013. The Korean wave: Korean media go global. London: Routledge.

Ma, K., 2013. Korean cinema, Chinese characteristics. Film business Asia, 7 October, Available from: http://www.filmbiz.asia/news/korean-cinema-chinese-characteristics [Accessed 2 July 2015].

Meyer-Clement, Elena, 2015. The evolution of Chinese film policy: how to adapt an instrument for hegemonic rule to commercialization. International journal of cultural policy, doi:10.1080/10286632.2015.1068764.

Miller, Toby, et al., 2005. Global hollywood 2. London: BFI.

Moran, Albert, 1996. Film policy: international, national and regional perspectives. In: Jannifer Craik, Tony Bennett, Ian Hunter, Colin Mercer, and Dugald Williamson, eds. Culture: policies and politics. London: Routledge.

Parc, Jimmyn, 2016. The effects of protection in cultural industries: the case of the Korean film policies. International journal of cultural policy, doi:10.1080/ 10286632.2015.1116526.

Vlassis, Antonios, 2015. Soft power, global governance of cultural industries and rising powers: the case of China. International journal of cultural policy, doi:10.1080/ 10286632.2014 .1002487$.

Yecies, Brian, 2010. Inroads for cultural traffic: breeding Korea's cinematiger. In: D. Black, S. Epstein, and A. Tokita, eds. Complicated currents: media production, the Korean wave, and soft power in East Asia, Monash University EPress.

Yoon, J. and Ji, Y., 2015. Anatomy of success in Korea-China co-productions with focus on top 4 films. Korean film biz zone, 7 May, Available from: http://www.koreanfilm.or. $\mathrm{kr} / \mathrm{jsp} /$ news/features.jsp?blbdComCd $=601013 \&$ seq $=217 \&$ mode $=$ FEATURES_VIEW [Accessed 2 July 2015].

Zhang, Weihong, 2010. China's cultural future: from soft power to comprehensive national power. International journal of cultural policy, 16 (4), 383-402. 